\title{
EL MAR Y LA TEMPESTAD: UN TÓPICO LITERARIO DESDE EL YAMBO DE LAS MUJERES DE SEMÓNIDES DE AMORGOS A LA ANDRÓMACA DE EURÍPIDES
}

\author{
JUAN TOBÍAS NÁPOLI \\ Centro de Estudios Helénicos \\ Universidad Nacional de La Plata-CONICET (Argentina)
}

A Filomena, filia luminis

\begin{abstract}
Resumen: El mar y la tempestad se han convertido en tópico literario en la literatura occidental. Intentaremos mostrar, a través de un ejemplo del yambógrafo Semónides de Amorgos y de la Andrómaca de Eurípides, que, en realidad, el mismo valor simbólico que el tópico del mar y la tempestad alcanza en la lírica se replica en la tragedia: la metáfora está ya lo suficientemente cristalizada como para que se constituya en vehículo para expresar la presentación de los personajes.
\end{abstract}

Palabras clave: Semónides, Eurípides, Andrómaca, metáforas, tormenta.

El mar y la tempestad se han convertido en tópico literario desde la propia configuración de la literatura occidental. En particular, según señala Vicente Cristóbal López (2010: p. 21) el motivo de la tempestad constituye, en los textos antiguos, un tópico que cumple una distinta funcionalidad según el género literario en que se manifieste. De este modo, en la épica, el viaje y la tempestad marítima adquieren plasmación literaria como argumento. Sin embargo, el argumento se convierte a su vez en metáfora de la existencia humana, y el héroe que viaja por el mar y que lucha contra las tempestades es un símbolo ideal de cada uno de los hombres, que tiene sus metas y encuentra dificultades y obstáculos para acceder a ellas. En la historiografía, en cambio, la narración en prosa de unos sucesos presentados como ciertos y realmente acaecidos impone sus exigencias de racionalismo y de fidelidad a los hechos, sin posibilidad para magnificaciones o tergiversaciones. En la lírica, el tópico del mar y de la tempestad se mostrará de manera subordinada 
y secundaria a otro tipo de contenidos cambiantes, ya sea como imagen, como metáfora o como una alusión más libre y creativa. Siempre según Cristóbal López (2010: 24), en la tragedia, en cambio, el tópico aparece casi forzosamente en escenas de mensajero, y tiene un tratamiento narrativo que es equivalente casi en un todo con el tratamiento que recibe en el género épico.

Sin embargo, la evidencia de los textos parece indicarnos otra cosa. La división por géneros no resultará del todo adecuada para mostrar los valores que el tópico adquiere en su tratamiento literario. Intentaremos mostrar, a través de un ejemplo del yambógrafo Semónides de Amorgos y de la Andrómaca de Eurípides que, en realidad, el mismo valor simbólico que el tópico del mar y la tempestad alcanza en la lírica se replica en la tragedia, incluso sin necesidad de recurrir a los discursos de mensajero: la metáfora está ya lo suficientemente cristalizada como para que se constituya en vehículo para expresar la presentación de los personajes.

Para ello trabajaremos en primer lugar con un fragmento del yambo de Semónides de Amorgos ${ }^{1}$ sobre las mujeres (Fr. 7 West). Como señala Fernanda Brasete (2005: 153-164), ${ }^{2}$ las cualidades poéticas del yambo han merecido muchas veces comentarios nada elogiosos. ${ }^{3}$ Sin embargo, se trata del fragmento más extenso del género ${ }^{4}$ que, a

1 La ubicación temporal de Semónides de Amorgos no puede determinarse con precisión. Debe suponerse como más probable la primera mitad del siglo VII a. C., según argumentos de E. Pellizer \& I. Tedeschi en la "introducción" de su edición (1990: pp. ix-xvii). Sobre la mencionada cuestión puede verse también el estudio de E. Pellizer (1983: pp. 17-28). Las dificultades que suscitó la grafía del nombre parecen resueltas: en la Antigüedad, su nombre osciló entre una forma $\Sigma \mu \omega v i \delta \eta \varsigma$ y otra $\Sigma \varepsilon \mu \omega v i \delta \eta\rceil$. El gramático bizantino Georges Choeroboscos demuestra sin embargo que el nombre de este poeta se escribía con $|\varepsilon|$, y se diferenciaba de este modo del poeta Simónides de Ceos, que perteneció al siglo V a. C.

2 Hemos seguido su interesante artículo para muchas de las cuestiones generales acerca del yambo.

3 Una reseña crítica de las interpretaciones poco favorables que este poema ha merecido por parte de los estudiosos puede encontrarse en la "Introducción" de la edición de H. Lloyd-Jones (1975: pp. 22-3). Eva Stehle (1997: p. 337) señaló que el poema es un “compendium of topoi”. Francisco R. Adrados (1990: p. 147) sustenta, en cambio, que el poema no es una gran obra poética, "pero sí un importante documento para la historia del espíritu griego". Cf. el estudio de Thomas K. Hubbard (1994: pp. 175-97).

4 Edmonds (1931) fue uno de los primeros en vincular los términos elegía y yambo en el marco de la poesía griega. El término yambo tiene una etimología y origen oscuro y, en la antigüedad, no designó un género poético codificado y compuesto en un metro específico. Cfr., al respecto, el capítulo I.3: "Iambus - the Problem of Terminology", de K. Bartol (1993). Tan así resulta, que la poesía yámbica arcaica admite una variedad de metros, como los trímetros yámbicos, los tetrámetros trocaicos y los epodos de Arquí- 
pesar de estar incompleto, ${ }^{5}$ se ofrece como uno de los más antiguos y curiosos testimonios de misoginia en la literatura occidental. La enciclopedia Bizantina conocida como Suda, un léxico compuesto alrededor del siglo X de nuestra era, le atribuye a Semónides una producción constituida por dos libros de elegías, unos yambos, una historia de Samos y otros escritos. Ninguna de esas obras se ha conservado hasta nuestros días; sin embargo, sobreviven muchos fragmentos, entre los cuales el más largo (el Frag. 7) consta de 118 versos. Preservado por una cita de Estobeo, se trata de un poema sobre las mujeres, primera obra misógina de la literatura occidental, aunque pueden encontrarse algunos precedentes en Hesíodo. ${ }^{6}$ La poesía está destinada a un contexto predominantemente simposíaco, se adapta al momento de su performance y

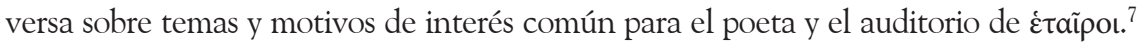
En este contexto, Semónides define a la mujer según su semejanza con diez razas o castas, creadas por Zeus, de las que ocho corresponden a animales (el perro, el asno, el cerdo, el zorro, la comadreja, el simio, la yegua y la abeja) y otras dos a elementos naturales (el mar y la tierra). Sólo se salva la mujer-abeja, prudente y laboriosa. Todas las otras tipologías de mujeres, cuya semejanza se presenta poéticamente como originadas en los seres naturales, presentan innumerables defectos o vicios: la mujer-tierra, vaga, encarna la necedad; la mujer-zorra es perversa; la mujer-comadreja hurta y causa daño a sus vecinos y es dañina y esquiva; la mujer-yegua, hermosa y lasciva, evita los trabajos

loco; además, los temas no se restringen a los de índole invectiva. Sobre estas cuestiones, cf. Martin West (1974: pp. 21-39), para quien el poema de Semónides es un "yambo genuino", y posiblemente la pieza más antigua de la poesía griega no-épica. Sobre el yambo en la poesía arcaica griega, véase Barron and Easterling (1985) y el estudio de Christopher G. Douglas, recogido en la edición de D. E. Gerber (1997: pp. 13-42).

5 Elyambo se interrumpe en el verso 118. Seguimos la edición de A. Pelizer y I. Tedeschi (1990).

6 En dos célebres pasajes del relato del mito de Prometeo (Teogonía 570-589 y Trabajos y días 60-82), Hesíodo narra la creación de la primera mujer (Pandora), a la que considera como un castigo de Zeus para la humanidad. Recuérdese que, como observa Jean-Pierre Vernant (1993: p. 59) "El mito de Pandora trae la justificación teológica de esa presencia necesaria de Eris en el mundo humano y de la obligación del trabajo que de ella resulta. [...] Pandora es un mal, pero un mal amable, una contrapartida y el reverso de un bien; los hombres, seducidos por su belleza, cubrirán de amor esa peste que les fue enviada, que no pueden soportar, pero sin la cual no pueden vivir: es el opuesto y la compañera de los hombres". Es notorio que, dentro de esta tradición misógina griega, Semónides va mucho más allá de la narración hesiódica: no se trata de un pasaje específico, sino que todo su poema está destinado a resaltar este carácter negativo de la mujer, y le atribuye a Zeus múltiples actos de creación que produjeron diez tipos femeninos distintos.

7 Cfr. Eva Stehle (1997: p. 239) y Robin Osborne (2001: pp. 45-64). 
serviles y la fatiga, y no toca el mortero ni levanta la basura: ni siquiera se sienta junto al hogar para evitar el hollín; la mujer-perro, iracunda y ladradora, representa la inmoralidad; la mujer-cerdo la suciedad; la mujer asno es laboriosa pero promiscua sexualmente; la mujer-simio, finalmente, que es la peor desgracia, representa la fealdad. Estas tipologías carecen de profundidad psicológica, ya que se trata de meros estereotipos de los distintos vicios; así, ya desde la época arcaica, la mujer se concibe y se trata como un genérico, mientras que el hombre se define como un ser individual. Con ellas, el poeta traza un cuadro bastante completo y complejo de la mujer de la época, presentado

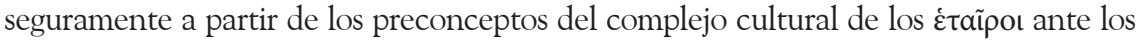
que representaría su producción.

En la poesía de Hesíodo encontramos, por primera vez en la literatura griega, la consideración de la mujer como uno de los males mayores de la humanidad. Tomando como cierta su influencia, convendría hacer notar que el yambógrafo de Amorgos no se limitó a repetir las versiones míticas utilizadas por el poeta beocio para explicar la creación de la mujer, ${ }^{8}$ sino que, por el contrario, se inspiró en un género de narrativa diferente, de amplia difusión popular y ya utilizado por la épica didáctica: la fábula. ${ }^{9}$ En el yambo de Semónides, la cuestión primordial no radica en la génesis de la mujer -que, como en el caso de Hesíodo, es una creación de Zeus- sino en el origen de su diversidad, en las distintas maneras de ser de su carácter. ${ }^{10}$ Basándose en el presupuesto de que un sistema coherente de tipos posibilitaba una comparación entre la naturaleza humana y la animal o natural, crea así

8 Cf. Teogonía, 570-90 y Trabajos y Días, 60-82. La mujer es una creación divina, un producto de mímesis y de techne, modelada a partir de agua y tierra a imagen de las diosas inmortales, pero para los hombres constituye un dolos terrible, un bello mal, causante de un sinnúmero de sufrimientos (Trabajos y Días, 82 ss.).

9 El aĩvoc del halcón y del ruiseñor narrado por Hesíodo en Trabajos y Días, 202-12, es comúnmente considerado como la fábula más antigua de la Literatura Griega. Hesíodo habría utilizado con finalidades retóricas muy precisas una antigua tradición fabulista, proveniente de las culturas orientales, que encerraba un mensaje ético y moral para los seres humanos en las situaciones o comportamientos protagonizados por animales.

El significado del término vóoc no es fácil de determinar; es posible suponer, sin embargo (como sugiere Pellizer-Tedeschi, p. 120), que aquí se utiliza en la acepción de "manera de pensar", equivalente por tanto a términos modernos como índole o carácter. Acerca de los numerosos paralelos entre las diversas culturas y épocas sobre la caracterización del género femenino véase: Johannes T. Kakridis (1962: pp. 3-10) y M. Rabanal Alvarez (1973: pp. 9-22). 
un esquema de pensamiento alegórico fundado en la analogía que, como se sabe, es característico del mundo de las fábulas de tipo esópico. ${ }^{11}$

En este raro fragmento de la poesía griega arcaica, el poeta de Amorgos reflexiona sobre la naturaleza femenina. Recordemos el inicio del poema:

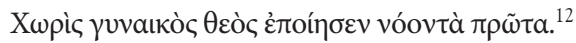

Este primer verso no es de fácil interpretación: es ambigua la semántica generada por la posición enfática de los lexemas Xwpiç... vóov y yuvaıkóc, que se halla en singular. Lloyd-Jones, ${ }^{13}$ editor de la obra, propone una interpretación confusa, basada en el significado del adverbio Xwpís (separadamente) y el uso del sustantivo yvvaıkó en singular. En su opinión, la ambigüedad de este primer verso reside, especialmente, en el hecho de que el poeta no menciona al hombre, que debería constituir una figura primordial en cualquier mito creacionista. Esa falla podría volverse insustancial si tomáramos en cuenta el contexto de elaboración: el género masculino estaría físicamente representado en la figura del narrador o en los miembros que constituían su auditorio simpótico ${ }^{14} \mathrm{y}$, en esas circunstancias, la interpretación esperada del verso "dios creó el nóos de la mujer diferentemente (o separadamente)", sería la de que el nóos femenino fue creado aparte del nóos del hombre. Lloyd-Jones agrega que si la intención del poeta hubiese sido referirse a la existencia de varios caracteres femeninos, sin duda habría utilizado yuvaıкós en plural.

Pellizer y Tedeschi, ${ }^{15}$ autores de la más reciente edición italiana del poeta, consideran que una interpretación más 'verosímil' del primer verso del poema consiste en pensar que "Zeus formó el nóos de la mujer diferente, unos en relación con otros": esa sería la idea original del poema y, con el tiempo, se convertiría en su leitmotiv. Sorprendentemente, el comienzo del poema de Semónides juega, de forma ambigua,

11 Cf. H.Lloyd-Jones, op cit., pp. 20-21.

12 En el principio Zeus hizo el carácter de la mujer de manera diferente. Todas las traducciones son nuestras.

13 Op. cit., 63-64. La misma interpretación es detallada por F. Rodríguez Adrados, op. cit., p. 155, n. 4 .

14 El hecho de que se trataba de un poema destinado al contexto simpótico fue insistentemente resaltado por autores como Lloyd-Jones, Pellizer-Tedeschi, E. Stehle y R. Osborne.

15 Cf. op. cit., pp. 119-120. Reaccionando a la interpretación de Lloyd-Jones, escriben: "Lipotesi che in un simposio, tra uomini si dovessa intendere immediatamente questo verso nel senso 'le donne hanno globalmente un diverso vóos da quello di noi uomini' è ingegnosa, ma no si trova conforme nel sucesivo contexto del giambo" (p. 119). 
con el nóos femenino, ${ }^{16}$ formando la idea de que la diversidad de los caracteres femeninos proviene de su propia esencia (vóoc), de su manera de ser, de su personalidad. La narración continúa describiendo a lo largo de 92 versos diez tipos diferentes de mujeres, nueve de ellos caracterizados negativamente y sólo uno digno de elogio. En la huella de los antiguos textos cosmológicos, en que el animal se considera como un ser homogéneo al hombre, y de las fábulas de tipo esópico, donde se concibe antropomorfizado, Semónides utiliza ocho animales como pistas simbólicas de los caracteres femeninos. Sólo que, curiosamente, las mujeres no sólo son consideradas semejante a los animales, sino como creadas por Zeus a partir de ellos. ${ }^{17}$ Además de los ocho tipos de mujeres descendientes de animales, se hace referencia a dos más, con diferente origen: la tierra y el mar -dos elementos naturales inanimados. Distinguiéndose de la versión hesiódica de la creación de Pandora (Trabajos y Días 60-70; Teogonía 57), formada por los dioses a partir de una mezcla de tierra y agua (barro), Semónides concibe, en contrapartida, estos mismos elementos naturales de manera separada ${ }^{18} \mathrm{y}$, por ello, da origen a dos tipos de mujeres de temperamento absolutamente diferentes: una mujer-tierra, caracterizada por su inercia e ineptitud ( $\pi \eta \rho o ́ v),{ }^{19}$ que la hace

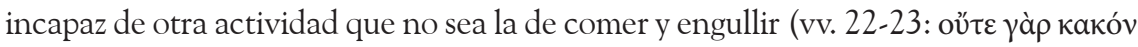

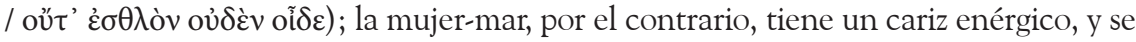

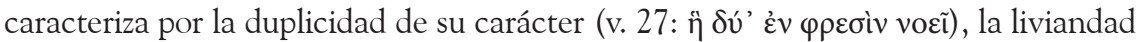

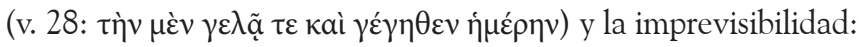

16 Esa ambigüedad es interpretada por N. Loraux (1981: p. 96) de una forma sincrética: la posición preliminar del adverbio $\chi \omega$ wís puede extender deliberadamente su campo semántico para referirse a la diversidad, tanto en términos colectivos (salvo el hombre) como individualmente (la variedad del género femenino).

17 Independientemente de los juicios negativos que se teje alrededor de esta "sátira" de Semónides, H. Fränkel (1993: p. 200) reconoce que "este poema tiene una considerable significación a causa de las formas mentales en las que se mueve. En primer lugar, aparece en él una idea fundamental en la antigua filosofía griega: la idea de lo material, o cuasimaterial, como representativo de cualidades, pues, según el texto literal de Semónides, las mujeres no son sólo semejantes a los diversos animales, sino que dios las ha hecho «de» ellos".

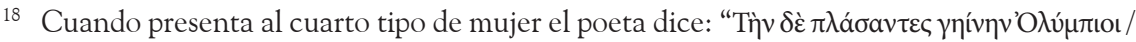

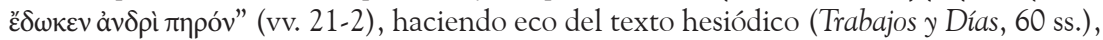
como señalan los editores Lloyd-Jones y Pellizer-Tedeschi, el quinto tipo de mujer es con-

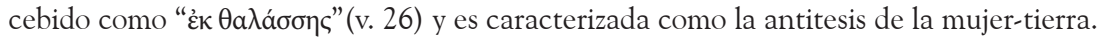

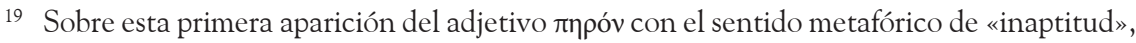
Veáse: Lloyd-Jones, ad v. 21-2. 


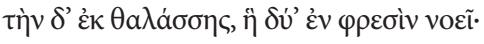

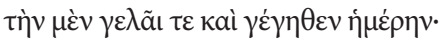

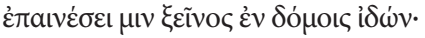

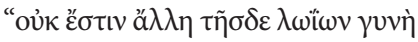

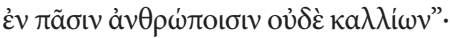

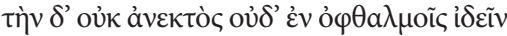

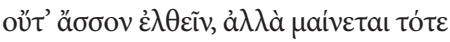

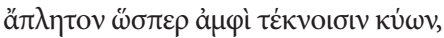

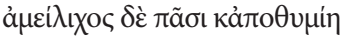

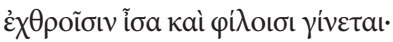

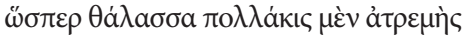

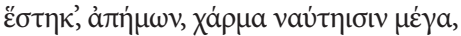

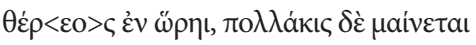

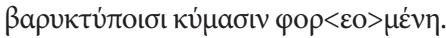

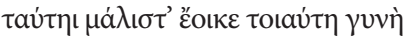

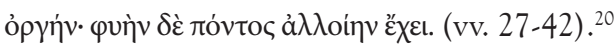

La tempestad marina, el mar encrespado es aquí el plano simbólico para definir el estado poco tratable y airado de una mujer, actitud contrastada además con su alternativa y opuesta: la calma marina, imagen de la benevolencia, del buen ánimo y de la tranquilidad de carácter. Las alusiones y referencias a los diversos caracteres femeninos resultan de un intento de objetividad que no podía dejar de presuponer un compromiso con el punto de vista masculino, compartido por el poeta y su auditorio.

Sin embargo, esta metáfora que vincula a la mujer con el mar calmo o tempestuoso no morirá aquí. Mientras Cristina Egoscozábal (2003: 7-25) estudia los precedentes de la utilización metafórica de los animales en el yambo de Semónides, Cristóbal López (2010: 21-41) analiza la descendencia de la metáfora marítima que

20 Mira ahora a la que ha nacido del mar, que tiene dos maneras de comportarse: un día ríe y está alegre. Un huésped que en su casa la mirare la alabará: "no hay entre todos los hombres una mujer más agradable ni más hermosa que ésta". Pero al otro día no se le puede mirar ni acercarse a ella; por el contrario, enloquece, inaccesible como la perra sobre sus cachorros. Áspera y desagradable por igual con amigos y enemigos; al mar se asemeja, que, muchas veces, sosegado y quieto, a los marineros llena de alborozo en la estación del verano, y muchas otras, airado, horriblemente brama, y alza y encrespa las hinchadas olas. Al mar es a lo que más se parece esta mujer por el carácter, y como el mar tiene una apariencia externa diferente. Téngase en cuenta que este fragmento se ha considerado sospechoso. Cf. Lloyd-Jones, Pellizer-Tedeschi y J. H. Hordern (2002: pp. 581-582). 
vincula a la mujer con el mar y la tormenta, saltando desde Semónides a Horacio y Virgilio para terminar en Garcilaso de la Vega y otros poetas renacentistas (como Juan de Arguijo y Andrés Fernández de Andrada). Ningún estudio vincula este complejo metafórico con la tragedia. Intentaremos completar, aunque sea brevemente, esta vacancia.

Como realidad objetiva, la mujer y el amor constituyen una presencia compleja e inquietante. Tan así es, que en la tragedia clásica no habrían podido presentarse mujeres enamoradas sobre la escena. ${ }^{21}$ El ejemplo del primer Hipólito habría disuadido a Eurípides de intentar nuevamente una osadía semejante. ${ }^{22}$ ¿Cómo presentar entonces la realidad de una mujer enamorada? En Eurípides, la metáfora aparece como una buena estrategia. ${ }^{23}$ Es bien sabido que en el mundo griego los papeles de quienes intervienen en una relación amatoria están claramente diferenciados: por un lado corren las actividades del amante (aquel que realiza de manera activa la acción de amar) y por otro las del amado (que tiene la obligación pasiva de dejarse amar). La relación es siempre asimétrica. ${ }^{24}$ Es por ello que la metáfora del jinete que sostiene las riendas del caballo al que ha domado expresa este aspecto desigual de la relación amatoria entre amante y amado. En este caso, el amor alcanza cierto grado de feliz concreción. Las riendas firmes del amante mantienen dominado al amado, como hace el jinete con un potro. Sin embargo, no va a terminar allí el modo de describir al amor: también se lo define como un reptil contra cuyo veneno no puede haber ningún remedio, o como un fuego que consume todo a su paso, o como un peso difícil de soportar, o como un viento borrascoso que llega de improviso, o como un milano, por la cruel volubilidad con la que huye, o como una nave que va a estrellarse contra una roca, o que marcha a la deriva, a merced

21 Cfr. Rodríguez Adrados (1995: p. 10), quien habla incluso de un proceso de deserotización del mito en la tragedia clásica (1995: p. 257). Ejemplifica este proceso de deserotización de la tragedia respecto de los mitos con lo que se realiza con las historias míticas de Agamenón y de Clitemnestra, con la de las Danaides, o con la de Antígona o la de Deyanira e, incluso, la de Alcestis. Sobre este último caso es interesante la afirmación de Adrados: no es una tragedia que trate acerca del amor, sino sólo de la virtud y del deber de la mujer casada. Cfr. (1985) en AAVV, pp. 177-200.

22 La sophrosyne en Andrómaca es estudiada por Boulter, P. N. (1966: 51-58), y como castidad en el Hipólito es discutida por Gregory (1997: pp. 61-62); sobre la auto restricción del tema amatorio en la tragedia puede consultarse North (1966: esp. p. 99).

23 Cfr. Nápoli, J. T. (1999: pp. 35-78). Del mismo autor (2001: pp. 87-104) y (2003: pp. 55-76).

24 Cfr. Calame, C. (2002). 
de las olas. En todos estos casos, se destaca el carácter trágico del amor que no está guiado por la convencional $\sigma \omega \varphi \rho o \sigma u ́ v \eta$. Por otra parte, el amante no ama, sino que busca y persigue, y pide y alcanza mediante ardides, mientras que el amado huye o concede o se escurre con astucia y engaño. En el desarrollo de las metáforas náuticas, el amado ofrece un puerto seguro a la nave que estuvo desvariando a merced de las olas y las tempestades, y el amante despreciado es una barca que no encuentra su rumbo. Muchos pasajes de las tragedias del primer período euripideo pueden explicarse a través de este conjunto de metáforas. La vinculación con Semónides seguramente no es directa, pero ambos comparten la misma idea griega del viaje por mar y la tempestad que allí se desata como símbolos que les permiten expresar la experiencia cotidiana del hombre: de aquel que intenta comprender la compleja realidad de la mujer o de aquel que lucha contra un destino que se le muestra hostil. En ambos casos, la descripción de la tormenta marina les permite matizar la comprensión de un fenómeno complejo. Vamos a ejemplificar algunas de estas metáforas con pasajes de Andrómaca.

Célebre es el pasaje del primer episodio en que Hermíone le habla a una suplicante Andrómaca, y justifica su enojo en contra de la esposa de Héctor porque ha sido capaz de engendrar descendencia con Neoptólemo, hijo del asesino de su esposo: los bárbaros como Andrómaca y las griegas como Hermíone son claramente diferentes. Así lo testimonia en los versos 173-180:

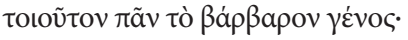

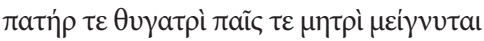

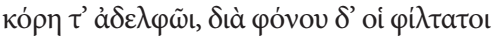

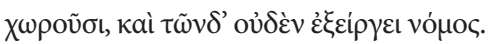

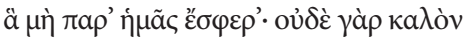

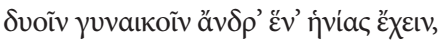

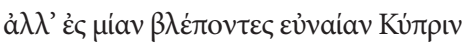

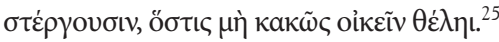

La tradicional auto-contención de la moral ateniense se expresa en estas palabras de Hermíone a través de la metáfora del jinete que sostiene las riendas de

25 De tal clase es toda la raza de los bárbaros: el padre se une con la hija y el hijo con la madre, y la muchacha con su hermano, y los seres más queridos se reemplazan a través del asesinato, y ninguna de estas cosas prohíbe la ley. No nos traigas estas costumbres. Pues no es bello que un solo hombre sostenga las riendas de dos mujeres, sino que, mirando a una sola Cipris (la que preside la unión nupcial) amen a quien no quiera vivir malamente. 
dos mujeres. Desde esta perspectiva condena la poligamia. Sin embargo, también las metáforas náuticas servirán para expresar esta relación amatoria. Ellas aparecerán concentradas en el final de la tragedia, y sirven para describir las conductas de los hombres que no han sabido gobernar su vida, incluso en el tema erótico. Así lo dirá Peleo cuando hable con Menelao. Criticará abiertamente la conducta de las mujeres espartanas y de la propia Helena, ejemplo de libertinaje, en el que caen por culpa de su educación. El pasaje que comentamos (versos 610-613) contiene una nueva metáfora náutica, que se pierde un poco en la traducción: el verbo griego

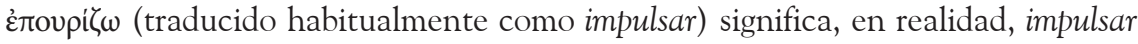
las velas con un viento favorable. Este viento favorable jamás impulsó, en la visión de Peleo, las velas del pensamiento de Menelao en la dirección adecuada, sino que lo llevó a la deriva por los senderos inhóspitos que describe a continuación:

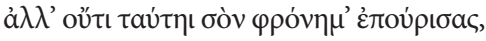

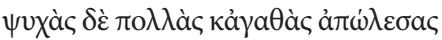

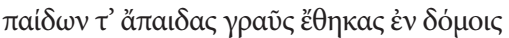

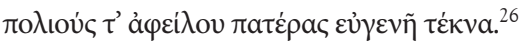

Peleo ingresa a escena. Viene en auxilio de Andrómaca. Va a dirigirle la palabra, como medio de resolver su situación. Para ello, utilizará la misma metáfora náutica que utilizará más tarde respecto de Menelao (cfr. vv. 554-8): el viento favorable que hincha las velas lleva la nave a puerto, y Peleo intenta que este viento salve a Andrómaca, a quien se dirige en primer lugar:

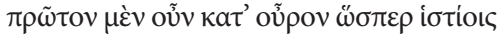

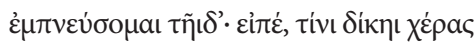

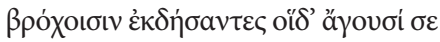

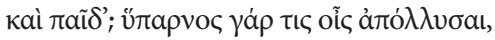

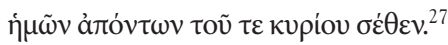

26 Sin embargo, nunca impulsaste tu pensamiento (nunca impulsaste las velas de tu pensamiento con un viento favorable) en esta dirección, sino que perdiste muchas y excelentes vidas, y dejaste en las casas a muchas ancianas sin hijos y a encanecidos padres los privaste de sus nobles descendientes.

27 En primer lugar, entonces, como lo hace el viento contra las velas, soplaré hacia ésta. Dime: ¿con qué justicia, después de haberte atado las manos con ligaduras, los conducen éstos a ti y a tu hijo? Pues mueres como una oveja que amamanta a su cordero, una vez que yo y tu señor estuvimos fuera. 
Nuevamente, la metáfora náutica sirve para marcar los distintos momentos de la tragedia. En este caso, el instante en que se ha resuelto la tragedia de Andrómaca, temerosa de la venganza que querían ejecutar en su contra Hermíone y Menelao. La nave de su vida, después de atravesar la zozobra de la tempestad, ha llegado hasta Peleo, quien se constituye en el puerto que está al reparo de vientos hostiles. A partir de allí comenzará la tragedia de Hermíone, temerosa de la venganza que Neoptólemo pudiera tomar en su contra, una vez que fue abandonada por Menelao. Peleo manifiesta claramente esta conclusión (vv. 747-9):

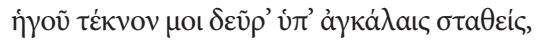

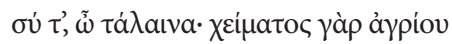

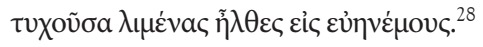

La vida de la mujer es similar a una barca en medio de la tempestad. Los brazos del protector son un puerto seguro que la protege de los vientos. La tragedia de Hermíone comienza a continuación. La resolución será la misma. Una nueva metáfora náutica compara a Hermíone con una barcaza que, llegada a la costa, es abandonada por su propietario para seguir su camino tierra adentro. Cumplida su misión, el barco es abandonado. Menelao se ha servido de Hermíone de la misma manera, y la ha abandonado. Hermíne ahora queda a la deriva, abandonada de un amor insano e imposible (vv. 854-855):

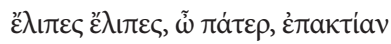

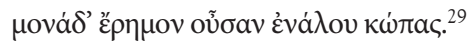

Sin embargo, la situación de Hermíone no ha llegado todavía a su fin. Aparece en escena Orestes, a quien había estado prometida con anterioridad. Para describir su nueva situación, echa mano de la misma metáfora anterior. La continuidad de la metáfora náutica lleva a Hermíone, que se había visto a sí misma como una barcaza abandonada, a considerar a Orestes, que llega impensada e inopinadamente a rescatarla, como un puerto seguro después de la tormenta. Nuevamente, la desmesura define su conducta (vv. 891-892):

28 Condúceme, hijo mío, una vez que te coloques debajo de mis brazos; y tú también, oh desdichada: pues después que has encontrado una salvaje tempestad, has llegado hasta un puerto abrigado del viento.

29 Me has abandonado, me has abandonado, padre, a mí, sola junto al borde del mar, como si fuera una barca en la costa. 


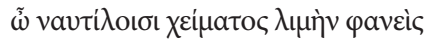

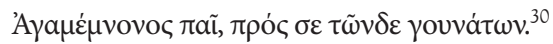

Hermíone reconoce su error. ${ }^{31}$ Reconoce incluso que lo que ha desencadenado en su tragedia ha sido este sentimiento desbordado del amor. Así lo dice en los versos 937-939, profundizando la misma metáfora, atraída por la referencia a las sirenas: así como, según el mito, las sirenas, con sus cantos engañadores, hacen naufragar los barcos que se acercan a ellas, así también Hermíone escucha a estas amigas-sirenas, que hinchan de locura el velamen de su barco, provocando su naufragio:

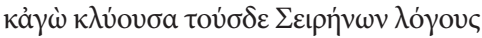

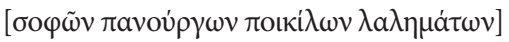

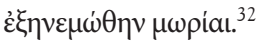

Un mensajero llega de Delfos. La trama se ha cerrado. Neoptólemo morirá asesinado, dejando en profunda congoja a Peleo, más allá de las consoladoras palabras de la diosa Tetis, que aparece ex machina al final de la tragedia. La muerte de Neotólemo es descripta también como el último acto de una batalla naval: se compara a Neoptólemo con la nave que ha sido acometida por un barco enemigo, y debe retroceder ante la embestida (vv. 1117-21):

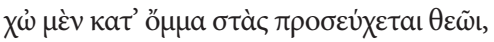

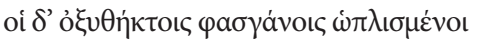

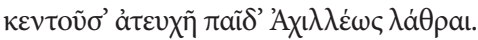

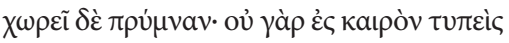

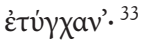

30 iOh puerto que apareces a los navegantes después de la tormenta, hijo de Agamenón!, me postro ante tus rodillas.

31 Cfr. Albini, U. (1974: pp. 83-95).

32 Y yo, después de escuchar estas palabras de sirenas, de sabias habladoras, sutiles y astutas, fui inflada por la locura.

33 Y él, puesto ante la vista de todos, dirige su ruego al dios. Sin embargo, armados con agudas espadas, ellos aguijonean a escondidas al indefenso hijo de Aquiles. Y retrocede la popa: pues todavía no se encontraba golpeado. 
A lo largo de toda la tragedia, las relaciones entre los personajes han estado condicionadas por un sentimiento vinculado con el amor y los celos. ${ }^{34}$ Se ha hablado acerca de ello, pero no se lo ha hecho con las palabras propias. En todo caso, el conjunto de metáforas sobre las temáticas vinculadas con el amor han servido de sucedáneo para describir un conjunto de acciones incomprensibles en la expresión directa. El lenguaje metafórico marítimo sirvió entonces para comprender mejor la complejidad de unas relaciones humanas que no pueden explicarse más a partir de la simple referencia a las instituciones sociales de la polis. Ese ha sido el gran mérito de Eurípides: sobreponerse a las constricciones de su época para expresar con una profundidad nueva y moderna esta complejidad de las relaciones humanas.

El tópico de la borrasca marina, imagen y reflejo de las condiciones vitales de los antiguos, se convirtió desde muy pronto, y de manera constante de la epopeya a la tragedia (pasando por la lírica), en metáfora de las difíciles condiciones en que debe desenvolverse la humanidad para alcanzar sus objetivos. En Semónides, la mujer misma se compara, en términos misóginos, con el mar en calma y en tempestad. En Eurípides, las mujeres son barcas que deben atravesar esta tempestad, y el amante es el puerto seguro en que encuentran abrigo. ${ }^{35}$ En ambos casos, la tempestad del mar sirve como metáfora para simbolizar las conmociones y obstáculos espirituales que debe atravesar la humanidad cuando busca el sosiego que la vida pocas veces ofrece. La experiencia poética permite comprender la compleja realidad de la mujer o de quien lucha contra un destino que se le muestra hostil, para disfrutar mejor de la plenitud del mar en calma, pasadas las tormentas de la existencia.

BibliografíA

Las citas están tomadas de las siguientes ediciones:

\section{Semónides:}

Pellizer, E. \& I. Tedeschi (1990) Semónides. Testimonia et Fragmenta, Roma. Lloyd-Jones, H. (1975) Females of the Species. Semonides on Women, New Jersey.

34 López Férez (1976: pp. 369-393) estudia con mucha precisión la cuestión del vocabulario en Andrómaca.

35 Sobre la misoginia en Eurípides, cfr. March, J. (1990: pp.32-75). 


\section{Andrómaca:}

Diggle, J. (1981, 1984 y 1995) Euripides Fabulae, Oxford, vols. I, II y III.

Garzya, A. (1953) Andromaca, Napoli

GrÉGoire, H. et Méridier, L. (1950) Euripide, Tome V, Paris.

Lloyd, M. (1994) Euripides Andromache, with an Introduction, Translation and Commentary, Oxford.

Méridier, L. (1923) Euripide, Tome II, Paris.

MérIdier, L. (1961) Euripide, tome I, Paris.

Murray, G. (1978) Euripides Fabulae, Oxford, 3 vols.

Stevens, P. T. (1971) Euripides, Andromache, edición, introducción y comentario, Oxford, Clarendon Press.

Tovar, A. (ED.) (1997) Eurípides Tragedias. Alcestis, Andrómaca, Madrid.

Walton, J. M. (1991) Euripides Plays, 2 vols., London.

WeCKLeIn, N. (1911) Andromache, Leipzig-Berlin.

\section{Bibliografía citada:}

Albini, U. (1974) "Un dramma d' avanguardia: l' Andromaca di Euripide", Maia 26, pp. 83-95.

Barron, J. P. and P. E. Easterling (1985) "Elegy and Iambus", en The Cambridge History of Classical Literature: Greek Literature, P. Easterling and B. Knox (eds), Cambridge University Press.

BARTOL, Krystyna (1993) Greek elegy and iambus. Studies in ancient literary sources, Poznań, Polska.

Boulter, P. N. (1966) "Sophia and Sophrosyne in Euripides' Andromache", Phoenix, $\mathrm{XX} ; 51-58$.

Brasete, M. F. (2005) "Semónides de Amorgos, fr. 7", Ágora: estudos clássicos em debate: 153-164.

Burn, A. R. (1960) The Lyric Age of Greece, Oxford.

Calame, C. (2002) Eros en la Antigua Grecia, Madrid.

Cavarzere, A., A. Aloni and A. Barchiesi (Eds.) (2001) Iambic Ideas. Essays on a Poetic Tradition from Archaic Greece to the Roman Late Empire, Rowman and Littlefield Publishers, Maryland.

Cristóbal López, V. (1988) "Tempestades épicas", Cuadernos de investigación filológica 14: 125-148. 
Douglas, Christopher G. (1997) en D. E. Gerber, A Companion to the Greek Lyric Poets, Leiden-New York-Köln: pp. 13-42.

Easterling, P. E. \& B. M .W. Knox (ed.) (1987) The Cambridge of Classical Literature, Vol I, Greek Literature, Cambridge.

Edmonds, J. M. (Ed.) (1931) Elegy and Iambus, with an English Translation, Cambridge, Harvard University Press, London, Volume II.

EgoscozÁbal, C. (2003) "Los animales del 'Yambo de las mujeres' de Semónides”, Estudios Clásicos 123: 7-25.

Fränkel, H. (1993) Poesía y Filosofía de la Grecia Arcaica, trad. esp. de R. Sánchez Ortiz de Urbina, Madrid.

Gerber, D. E. (1997) A Companion to the Greek Lyric Poets, Leiden-New York-Köln. Gregory, J. (1997) Euripides and the Instruction of the Athenians, Michigan.

Hordern, J. H. (2002) “Semonides, fr. 7. 41-2”, CQ 52: 581-582.

Hubbard, T. K. (1994) "Elemental Psychology and the Date of Semonides of Amorgos” AJPh 115.2: 175-97.

Kakridis, J. T. (1962) "Zum Weiberiambus des Semonides": Wiener Humanistische Blätter 5: 3-10.

Laguna Mariscal, G. (2000) "El tópico de la tormenta de amor: de la poesía grecolatina a la tradición clásica”, en M. A. Márquez et al. (Eds.) Actas del XII Simposio de la Sociedad Española de Literatura General y Comparada, Huelva: 435-442.

LASSERre, F. (1984) LaFable, Entrettienssurl'antiquitéclassique30, Vandoeuvres-Geneve. Lewis, S. (2002) The Athenian Woman. An conographic Handbook, London.

Lonsdale, S. H. (1989) "Hesiod's Hawk and Nightingale (OP. 202-12): Fable or Omen?" Hermes 117: 403-412.

López Férez, J. A. (1976) "El tema del amo y el esclavo en la Andrómaca de Eurípides", en Cuadernos de Filología Clásica, 11: 369-393.

Loraux, N. (1981) Les Enfents d'Athéna, Paris.

March, J. (1990) "Euripides the mysogynist?", en Powell, J. (Ed.) Euripides, women, and sexuality, London, 32-75.

Mossé, C. (1983) La femme dans la Grèce antique, Paris.

NÁpoli, J. T. "El discurso de la nodriza en el prólogo de Medea de Eurípides y la cuestión del amor", Synthesis, Vol. 10, año 2003, pp. 55-76.

NÁpoli, J. T. "La 'locura amorosa' en Hipólito de Eurípides: análisis filológico de la $\mu$ wpía femenina”, Synthesis, Vol. 8, año 2001, pp. 87-104 
NÁpoli, J. T. "Los celos de Hermíone en Andrómaca y la cuestión del amor en Eurípides”, Synthesis, Vol. 6, año 1999, pp. 35-78.

North, H. (1966) Sophrosyne: Self-Knowledge and Self-Restraint in Greek Literature, Ithaca.

Osborne, R. (2001) "The Use of Abuse: Semonides 7", PCPS 47: 45-64.

Pellizer, E. (1983) "Sulla cronologia, la vita e l'opere di Semonide Amorgino", QUCC 14: 17-28.

Rabanal Alvarez, M. (1973) "El Yambo de las mujeres de Semónides de Amorgos", Durius I: 9-22.

Ramajo Caño, A. (2001) "La execración de la navegación, el navigium amoris y el propempticón en la lírica áurea”, Boletín de la Real Academia Española 81: 507-528.

RodríGuez Adrados, F. (1985) "El amor en Eurípides”, en AAVV El descubrimiento del amor en Grecia, Madrid, pp. 177-200.

Rodríguez Adrados, F. (1990) Líricos arcaicos. Elegíacos y Yambógrafos Arcaicos, Vol I, Madrid.

Rodríguez Adrados, F. (1995) Sociedad, amor y poesía en la Grecia antigua, Madrid.

Roscalla, F. (2003) "Il giambo di Semonide contro le donne e la dizione aedica" QUCC 73.1: 115-113.

Stehle, E. (1997) Performance an Gender in Ancient Greece, Princeton.

Verdenius, W. J. (1968) "Semonides über die Frauen: ein Kommentar zu Fr. 7", Mnemosyne 21: 132-158.

Vernant, J. P. (1993) Mito y pensamiento en la Grecia Antigua, Ariel.

West, M. (1974) Studies in Greek Elegy and Iambus, Berlin-New Cork.

Abstract: The sea and the storm have become a literary commonplace in Western literature. We will try to show, through an example of Semonides of Amorgos and Andromache of Euripides, which, in fact, the same symbolic value that the topic of the sea and the storm reaches the lyric is replicated in the tragedy: the metaphor is crystallized enough so that becomes a vehicle for expressing the presentation of the characters.

Keywords: Semonides, Euripides, Andromache, metaphors, storm. 